\title{
Effect of Solubility Enhancers on the Release of Carbamazepine from Hydrophilic Polymer Based Matrix Tablet
}

\author{
Sharifa Sultana ${ }^{1}$, Shimul Halder ${ }^{2}$, A.K. Lutful Kabir ${ }^{2}$ and Abu Shara Shamsur Rouf ${ }^{2}$ \\ ${ }^{1}$ Faculty of Science \& Technology, Daffodil International University, Dhaka, Bangladesh \\ ${ }^{2}$ Department of Pharmaceutical Technology, University of Dhaka, Dhaka-1000, Bangladesh
}

Received: May 15, 2014; Accepted: August 30, 2014; Published (web): December 31, 2014

\begin{abstract}
In the present study, an attempt has been taken to evaluate the effect of sodium lauryl sulphate (SLS) and glyceryl mono stearate (GMS) as solubility enhancers on the release profile of a poorly soluble drug, carbamazepine. Matrix tablets of carbamazepine were prepared by wet granulation technique using hydrophilic polymers (10\% of Methocel K15 MCR and 10\% of Methocel K100LV CR) as release controlling agents. Varying amounts of SLS and GMS were used in six different formulations to observe the impact on the release rate and mechanism of drug release. The dissolution study of carbamazepine from these extended release matrix tablets was conducted for 24 hours using basket method in $900 \mathrm{ml}$ distilled water as dissolution medium. The data obtained from the dissolution studies were explored and explained with the help of zero order, Higuchi, first order, KorsmeyerPeppas and Hixson-Crowell equations. It was found that the dissolution rate of carbamazepine with the formulation containing SLS was higher than GMS containing formulation and increased concentration of SLS increasing the release rate. Where there was no SLS or smaller amount of SLS or GMS release rate was decreased. Formulation having equal ratio of SLS and GMS did not show the desire release profile. The drug release mechanism followed mainly super case II transport. These results clearly demonstrated that the dissolution rate, extent and mechanism of carbamazepine release could be changed by optimizing the amount of SLS and GMS in the tablet formulation.
\end{abstract}

Key words: Carbamazepine, extended release, hydrophilic matrix, sodium lauryl sulphate, glyceryl mono stearate

\section{INTRODUCTION}

Carbamazepine is a poorly water-soluble antiepileptic drug. Poorly soluble drugs are associated with slow drug absorption leading to inadequate and variable bioavailability. ${ }^{1,2}$ Most formulation strategies for such drugs are targeted at enhancing their dissolution rate and/or solubility in vivo by achieving their fine dispersion at absorption level. $^{2-4}$ General strategies to enhance their dissolution patterns rely upon either changing the dissolution medium $\mathrm{pH}$, or adding solubilizer such as surfactants and cyclodextrin derivatives into the dissolution medium. ${ }^{5-11}$ The incorporation of a surfactant or suspending agent into a formulation can

Correspondence to: Shimul Halder

E.mail: shimulpht@du.ac.bd

Dhaka Univ. J. Pharm. Sci. 13(2): 167-173, 2014 (December) enhance solubility but may have detrimental impact on regulatory approval or overall stability of the formulation. By incorporating a small amount of a surfactant (often less than 0.2 per cent) in a formulation, it may be possible to enhance the solubility by increasing the exposure of poorly soluble drugs' physical surfaces to gastrointestinal fluid and facilitate dissolution or dispersion. There is a threshold of usability for surfactants - in vivo side effects notwithstanding - above which they begin to depress solubility and complete release often becomes problematic for the formulation, especially within matrix-based systems. ${ }^{12}$ The addition of surfactant in matrix formulations has generally resulted in a faster drug release rate. ${ }^{13-15}$ Moreover, the findings of a lot of investigations showed that the presence of surfactant influenced the tablet disintegration rate, producing a finer dispersion of 
disintegrated particles with correspondingly larger surface area for drug dissolution.

\section{MATERIALS AND METHODS}

Materials. The following materials were used in the present study: carbamazepine (FIS, Italy), methocel K15M CR and methocel K100 LVCR (Colorcon, USA), sodium lauryl sulphate (SLS) (Weichers \& Helm), glyceryl monostearate (Chemical Canagement Consortium, Germany), colloidal silicon dioxide (aerosil 200, Degussa Cobat, Germany), and magnesium stearate (Wilfrid Smith Ltd., UK.).

Solvents and reagents. Methanol (Merck, Germany), methylene chloride (Merck, Germany), distilled water were used.

HPLC analysis. The standard drug, carbamazepine as well as sample solutions were analyzed by HPLC for checking purity and identity (Figures 1 and 2).

Preparation of matrix tablets. Tablets were prepared by wet granulation technique (Table 1). In formulation F-1, the active ingredient carbamazepine and release retardant methocel K15M CR were blended together in a polybag for
10 minutes. Then, the blend was sieved through $0.425 \mathrm{~mm}$ mesh (SHIVA, India) and taken in a stainless still bowl. Purified water was added with blend and mixed well to form granules. In formulation F-2 and F-3, SLS was dissolved into $50 \mathrm{ml}$ water. SLS solution was added with blend and mixed well to form granules. In the formulation F-4 and F-5 GMS was added with active ingredient and granules were prepared by same way, exception is the addition of purified water as granulating fluid instead of SLS solution. In the formulation F-6, active ingredient, release retardants methocel K15M CR and GMS were blended together and form the granules by adding SLS solution. The granules were dried into a tray drier (Classic Scientific, India) at $60^{\circ} \mathrm{C}$. LOD of the granules were maintained within $0.80 \%$ to $1.20 \%$. Finally the dried granules were sieved through $0.85 \mathrm{~mm}$ mesh then blended again with release retardant methocel K100LVCR in a polybag for 5 minutes. The mix was blended in a laboratory designed small drum blender (China) finally with colloidal silicon dioxide (aerosol 200) and magnesium stearate (by passing through $0.425 \mathrm{~mm}$ mesh) for 1 minute and tablets of $200 \mathrm{mg}$ mass were compacted using a Clit Tablet Press (USA) with 8.9-mm flat circular punch and die sets. The compaction force was varied to obtain the desired hardness.

Formulations. The formulations of tablets are shown in Table 1.

Table 1. Proposed formulations of carbamazepine matrix tablets.

\begin{tabular}{ccccccccc}
\hline $\begin{array}{c}\text { Formulation } \\
\text { code }\end{array}$ & $\begin{array}{c}\text { Carbamazepine } \\
(\mathrm{mg})\end{array}$ & $\begin{array}{c}\text { Methocel } \\
\text { K15M CR } \\
(\mathrm{mg})\end{array}$ & $\begin{array}{c}\text { Methocel } \\
\text { K100 LV } \\
\text { CR }(\mathrm{mg})\end{array}$ & $\begin{array}{c}\text { SLS } \\
(\mathrm{mg})\end{array}$ & $\begin{array}{c}\text { GMS } \\
(\mathrm{mg})\end{array}$ & $\begin{array}{c}\text { Aerosil } \\
200 \\
(\mathrm{mg})\end{array}$ & $\begin{array}{c}\text { Magnesium } \\
\text { stearate } \\
(\mathrm{mg})\end{array}$ & $\begin{array}{c}\text { Total } \\
\text { weight } \\
(\mathrm{mg})\end{array}$ \\
\hline F-1 & 200 & 25 & 25 & 0.0 & 0.0 & 1.25 & 1.25 & 252.5 \\
F-2 & 200 & 25 & 25 & 1.25 & 0.0 & 1.25 & 1.25 & 253.8 \\
F-3 & 200 & 25 & 25 & 2.50 & 0.0 & 1.25 & 1.25 & 255.0 \\
F-4 & 200 & 25 & 25 & 0.0 & 1.25 & 1.25 & 1.25 & 253.8 \\
F-5 & 200 & 25 & 25 & 0.0 & 2.50 & 1.25 & 1.25 & 255.0 \\
F-6 & 200 & 25 & 25 & 1.25 & 1.25 & 1.25 & 1.25 & 255.0 \\
\hline
\end{tabular}

\section{Physical evaluation of granules}

Bulk density. LBD (loose bulk density) and TBD (tapped bulk density) were determined by taking $2 \mathrm{~g}$ of powder from each formula, previously lightly shaken to break any agglomerates and pouring into a $10 \mathrm{ml}$ measuring cylinder. After the initial volume was observed, the cylinder was allowed to fall under its own weight onto a hard surface from the height of $2.5 \mathrm{~cm}$ at 2 second intervals. The reading of tapping was continued until no further change in volume was noted. Using the following equation LBD and TBD was calculated:

$$
\begin{aligned}
\mathrm{LBD}= & \text { Weight of the powder / initial volume of } \\
& \text { the packing } \\
\mathrm{TBD}= & \text { Weight of the powder / Tapping volume } \\
& \text { of the packing }
\end{aligned}
$$


Compressibility index. The compressibility index of the granules was determined by Carr's compressibility index:

$$
\text { Carr's index }(\%)=\{(\text { TBD }- \text { LBD }) \times 100\} / T B D
$$

Total porosity. Total porosity was determined by measuring the volume occupied by a selected weight of powder $\left(\mathrm{V}_{b u l k}\right)$ and the true volume of granules (the space occupied by the powder exclusive of spaces greater than the intermolecular space (V)

Porosity $(\%)=\left(V_{\text {bulk }}-V\right) / V_{\text {bulk }} \times 100$

Angle of repose. The angle of repose of granules was determined by the funnel method. The accurately weighed granules were taken in a funnel. The height of the funnel was adjusted in such a way that the tip of the funnel just touched the apex of the heap of the granules. The granules were allowed to flow through the funnel freely onto the surface. The diameter of the powder cone was measured and angle of repose was calculated using the following equation:

Angle of repose, $\theta=\tan ^{-1} \mathrm{~h} / \mathrm{r}$

here, $\mathrm{h}=$ height of the powder cone,

$r=$ radius of the powder cone.

Moisture content. Moisture content of granules was determined using Mettler Karl Fischer titrator. About $120 \mathrm{mg}$ granules was weighed and added into the reagent solutions of the instrument, which was stirred and the tare weight was fed into the instrument. Then after certain duration of time the moisture content as \%w/w was read on the monitor.

Drug content. An accurately weighed amount of powdered carbamazepine (200 mg) was extracted with methanol and the solution was filtered through $0.45-\mu$ membrane filter paper. The drug content was measured by HPLC with UV detector (SHIMADZU, Japan) at $230 \mathrm{~nm}$ after suitable dilution with mobile phase (water: methanol: methylene chloride = 600:450:45) according to USP. (Figure: 1, 2).

\section{Physical evaluation of carbamazepine matrix tablet}

Hardness and friability. For each formulation, the hardness and friability of 6 tablets were determined using the Monsanto hardness tester
(England) and the Roche friabilator (ERWEKA, Germany) respectively.

Diameter and thickness. The diameter and thickness of the tablet was determined using digital vernier calipers (Neiko Tools, Model: 11033A, USA). Five tablets from each batch were used, and average values were calculated.

Average weight and weight variation test. To study average weight and weight variation, 20 tablets from each formulation were weighed using an analytical electronic balance (Sartorius, Germany) and the test was performed according to the official method.

Drug content. Ten tablets were weighed individually, and the drug was extracted with methanol. Drug content determined by the same way of granules.

Dissolution studies. The in vitro dissolution study was carried out using USP Type -I dissolution apparatus (Electrolab, India). The study was carried out in $900 \mathrm{ml}$ of distilled water. The dissolution medium was kept in thermostatically controlled water bath, maintained at $37^{\circ} \mathrm{C} \pm 0.5^{\circ} \mathrm{C}$. Basket rotation was adjusted to $100 \mathrm{rpm}$. At definite intervals, $5 \mathrm{ml}$ sample was withdrawn and analyzed spectrophotometricaly at $285 \mathrm{~nm}$ for the drug release by using UV-visible spectrophotometer (Shimadzu, UV-1601, Japan). At each time of withdrawal, $5 \mathrm{ml}$ of fresh corresponding medium was replaced into the dissolution flask.

Kinetic treatment of dissolution data. ${ }^{16-20}$ In order to describe the kinetics of the release process of drug in the different formulations, zero- order $\left(\mathrm{Q}_{\mathrm{t}}=\right.$ $\mathrm{Q}_{0}+\mathrm{K}_{0} \mathrm{t}$ ), first- order (in $\mathrm{Q}_{\mathrm{t}}=$ in $\mathrm{Q}_{0}+\mathrm{K}_{1} \mathrm{t}$ ), Higuchi $\left(\mathrm{Q}_{\mathrm{t}}=\mathrm{K}_{\mathrm{H}} \mathrm{t}^{1 / 2}\right)$ and Korsmeyer- Peppas $\left(\mathrm{Qt} / \mathrm{Q} \infty=\mathrm{Kt}^{\mathrm{n}}\right)$ and Hixson-Crowell models $\left(\mathrm{Q}_{0}{ }^{1 / 3}-\mathrm{Q}_{\mathrm{t}}^{1 / 3}=\mathrm{k}_{\mathrm{HC}} \times \mathrm{t}\right)$ were fitted to the dissolution data of optimized formulations using linear regression analysis. A value of $\mathrm{n}=0.5$ indicates case I (Fickian) diffusion or square root of time kinetics, $0.5<\mathrm{n}<1$ anomalous (non- Fickian) diffusion, $\mathrm{n}=1$ Case $-\mathrm{II}$ transport and $\mathrm{n}>1$ Super Case II transport. 


\section{RESULTS AND DISCUSSION}

The results of angle of repose indicated good flow properties of the granules which were further supported by lower compressibility index values. The percentage porosity values of the granules indicated that the packing of the granules might range from close to loose packing and also further confirming that the particles were not of greatly different sizes. The drug content in a weighed amount of granules of all formulations indicated that the granules possessed satisfactory flow properties, compressibility and drug content. The granules of different formulations were evaluated for angle of repose $23.75 \pm 0.01$ to $31.05 \pm$ 0.01 , generally values of angle of repose are rarely less than $20^{\circ}$, and values up to $40^{\circ}$ indicate reasonable flow properties. Loose bulk density $0.405 \pm 0.02$ to $0.446 \pm 0.02 \mathrm{~g} / \mathrm{ml}$ and tapped bulk density $0.468 \pm$ 0.03 to $0.540 \pm 0.01 \mathrm{~g} / \mathrm{ml}$ were observed. Compressibility index $13.46 \pm 0.012$ to $19.00 \pm$ $0.03 \%$, generally, compressibility index values up to $15 \%$ result in good to excellent flow properties, but readings above $25 \%$ indicates poor flowability. Moisture content 0.88 to $1.12 \%$, total porosity 9.756 \pm 0.04 to $18.96 \pm 0.04 \%$ and assay $98.68 \pm 0.04$ to $100.4 \pm 0.06 \%$ (Table- 2 ). All the results were found within the limits.

Table 2. Properties of granules of carbamazepine and excipients.

\begin{tabular}{|c|c|c|c|c|c|c|c|}
\hline $\begin{array}{c}\text { Formu- } \\
\text { lation } \\
\text { code }\end{array}$ & $\begin{array}{c}\text { Angle of } \\
\text { repose }\left(^{\circ}\right)\end{array}$ & $\begin{array}{c}\text { Loose bulk } \\
\text { density (LBD) } \\
(\mathrm{g} / \mathrm{mL})\end{array}$ & $\begin{array}{c}\text { Tapped bulk } \\
\text { density (TBD) } \\
(\mathrm{g} / \mathrm{mL})\end{array}$ & $\begin{array}{l}\text { Compressibili } \\
\text { ty index }(\%)\end{array}$ & $\begin{array}{l}\text { Moisture } \\
\text { content } \\
(\%)\end{array}$ & $\begin{array}{c}\text { Drug content } \\
(\%)\end{array}$ & $\begin{array}{c}\text { Total porosity } \\
(\%)\end{array}$ \\
\hline F-1 & $28.92 \pm 0.05$ & $0.416 \pm 0.02$ & $0.493 \pm 0.01$ & $15.62 \pm 0.02$ & 0.88 & $100.2 \pm 0.01$ & $15.38 \pm 0.03$ \\
\hline $\mathrm{F}-2$ & $26.57 \pm 0.05$ & $0.405 \pm 0.02$ & $0.500 \pm 0.01$ & $19.00 \pm 0.03$ & 0.98 & $99.20 \pm 0.03$ & $18.96 \pm 0.04$ \\
\hline $\mathrm{F}-3$ & $29.98 \pm 0.01$ & $0.458 \pm 0.03$ & $0.540 \pm 0.01$ & $15.03 \pm 0.04$ & 1.01 & $99.60 \pm 0.05$ & $15.15 \pm 0.06$ \\
\hline F-4 & $23.75 \pm 0.01$ & $0.446 \pm 0.02$ & $0.539 \pm 0.02$ & $17.25 \pm 0.06$ & 1.05 & $100.4 \pm 0.06$ & $17.14 \pm 0.05$ \\
\hline F-5 & $30.96 \pm 0.06$ & $0.405 \pm 0.02$ & $0.468 \pm 0.03$ & $13.46 \pm 0.012$ & 0.89 & $98.68 \pm 0.02$ & $9.756 \pm 0.04$ \\
\hline F-6 & $31.05 \pm 0.01$ & $0.423 \pm 0.03$ & $0.497 \pm 0.03$ & $14.89 \pm 0.01$ & 1.12 & $99.68 \pm 0.04$ & $11.11 \pm 0.01$ \\
\hline
\end{tabular}

The formulated matrix tablets met the pharmacopoeial requirements of uniformity of weight. All the tablets conformed to the requirement of drug content, as per USP. Hardness, \% friability, diameter and thickness, tensile strength were well within the acceptable limits. (Table 3) All formulations showed less than $1 \%(w / w)$ friability that indicates the ability of tablets to withstand shocks which may be encountered during transport. The manufactured tablets showed low weight variations and a high degree of drug content uniformity was found among different batches of the tablets, and drug content was more than $98 \%$.

Release kinetics. Based on pharmacokinetics the release of profiles of the formulated tablets was compared with the theoretical sustained release heeded to select the optimized formulation. To know the mechanism of drug release from these formulations, the data were treated according to zero order (cumulative amount of drag released versus time) equations along with Korsmeyer's (log cumulative parentages of in released versus log time) equations. The carbamazepine release rate kinetics was determined by multiple coefficients $\left(\mathrm{R}^{2}\right)$ for individual formulation (Table 4). From the correlation coefficient values, it appears that Higuchi model is the best-fitting model for carbamazepine release since higher " $\mathrm{R}$ " values were found for the whole release process, which indicates a diffusioncontrolled release. Diffusion is related to transport of the drug from the dosage matrix into the dissolution fluid, depending on the concentration. As the concentration gradient varies, the drug is released, and the distance for diffusion increases. This could explain why the drug diffuses at a comparatively slower rate as the distance for diffusion increases, which is referred to as the square-root kinetics or Higuchi's equation. In this experiment, the in vitro release profiles of the drug from all the formulations could be best expressed by Higuchi's equation, as the 
plots showed high linearity $\left(\mathrm{R}^{2}=0.924\right.$ to 0.954$)$. To confirm the diffusion mechanism, the data were fitted into Korsmeyer's equation. Almost all the formulations showed good linearity $\left(\mathrm{R}^{2}=0.906\right.$ to 0.959 ), with diffusional exponent $(\mathrm{n})$ values ranging from 0.957 to 1.221 , indicating that erosion type super case-II transport was the dominant mechanism of drug release. The diffusional exponent of batches indicates super case-II transport type of release mechanism i.e. drug release is by coupling of erosion and polymer matrix relaxation-and may indicate that drug release is controlled by more than one processes.

Table 3. Properties of carbamazepine matrix tablets.

\begin{tabular}{lccccccc}
\hline $\begin{array}{l}\text { Formu- } \\
\text { lation } \\
\text { code }\end{array}$ & $\begin{array}{c}\text { Average } \\
\text { weight } \\
(\mathrm{mg})\end{array}$ & $\begin{array}{c}\text { Weight } \\
\text { variation }(\%)\end{array}$ & $\begin{array}{c}\text { Diameter } \\
(\mathrm{mm})\end{array}$ & $\begin{array}{c}\text { Thickness } \\
(\mathrm{mm})\end{array}$ & $\begin{array}{c}\text { Hardness } \\
(\text { Newton })\end{array}$ & $\begin{array}{c}\text { Friability } \\
(\%)\end{array}$ & $\begin{array}{c}\text { Assay } \\
(\%)\end{array}$ \\
\hline F-1 & $252.5 \pm 0.02$ & $1.30 \pm 0.02$ & $8.9 \pm 0.02$ & $3.90 \pm 0.06$ & $100-125$ & 0.25 & $99.13 \pm 0.04$ \\
F-2 & $253.8 \pm 0.04$ & $2.10 \pm 0.02$ & $8.9 \pm 0.03$ & $4.20 \pm 0.04$ & $150-180$ & 0.45 & $98.65 \pm 0.06$ \\
F-3 & $255.0 \pm 0.05$ & $1.20 \pm 0.04$ & $8.9 \pm 0.02$ & $4.00 \pm 0.01$ & $150-180$ & 0.31 & $98.03 \pm 0.02$ \\
F-4 & $253.8 \pm 0.03$ & $2.75 \pm 0.02$ & $8.9 \pm 0.04$ & $4.20 \pm 0.03$ & $130-160$ & 0.36 & $99.15 \pm 0.03$ \\
F-5 & $255.0 \pm 0.06$ & $2.75 \pm 0.01$ & $8.9 \pm 0.05$ & $3.70 \pm 0.02$ & $130-150$ & 0.45 & $99.67 \pm 0.03$ \\
F-6 & $255.0 \pm 0.05$ & $1.50 \pm 0.03$ & $8.9 \pm 0.03$ & $4.00 \pm 0.02$ & $120-140$ & 0.27 & $100.1 \pm 0.01$ \\
\hline
\end{tabular}

Table 4. Release rate constants and $\mathbf{R}^{2}$ values for different release kinetics of tablets.

\begin{tabular}{|c|c|c|c|c|c|c|c|c|c|c|}
\hline \multirow{2}{*}{$\begin{array}{l}\text { Formula- } \\
\text { tion code }\end{array}$} & \multicolumn{2}{|c|}{ Zero order } & \multicolumn{2}{|c|}{ Higuchi } & \multicolumn{2}{|c|}{ First order } & \multicolumn{2}{|c|}{ Korsmeyer-Peppas } & \multicolumn{2}{|c|}{ Hixson-Crowell } \\
\hline & $\mathrm{K}_{0}$ & $\mathrm{R}^{2}$ & $\mathrm{~K}_{\mathrm{h}}$ & $\mathrm{R}^{2}$ & $\mathrm{~K}_{1}$ & $\mathrm{R}^{2}$ & $\mathrm{n}$ & $\mathrm{R}^{2}$ & $\mathrm{~K}_{\mathrm{HC}}$ & $\mathrm{R}^{2}$ \\
\hline F-1 & 1.866 & 0.822 & 10.18 & 0.929 & -0.010 & 0.859 & 1.119 & 0.906 & -0.034 & 0.847 \\
\hline $\mathrm{F}-2$ & 3.231 & 0.882 & 17.00 & 0.928 & -0.025 & 0.951 & 1.105 & 0.956 & -0.072 & 0.931 \\
\hline F-3 & 4.307 & 0.835 & 23.29 & 0.928 & -0.069 & 0.981 & 1.069 & 0.931 & -0.145 & 0.955 \\
\hline $\mathrm{F}-4$ & 3.012 & 0.916 & 15.52 & 0.924 & -0.021 & 0.972 & 1.221 & 0.959 & -0.064 & 0.958 \\
\hline F-5 & 3.851 & 0.844 & 20.72 & 0.929 & -0.039 & 0.960 & 1.164 & 0.927 & -0.101 & 0.930 \\
\hline F-6 & 3.246 & 0.856 & 17.58 & 0.954 & -0.026 & 0.963 & 0.957 & 0.939 & -0.076 & 0.933 \\
\hline
\end{tabular}

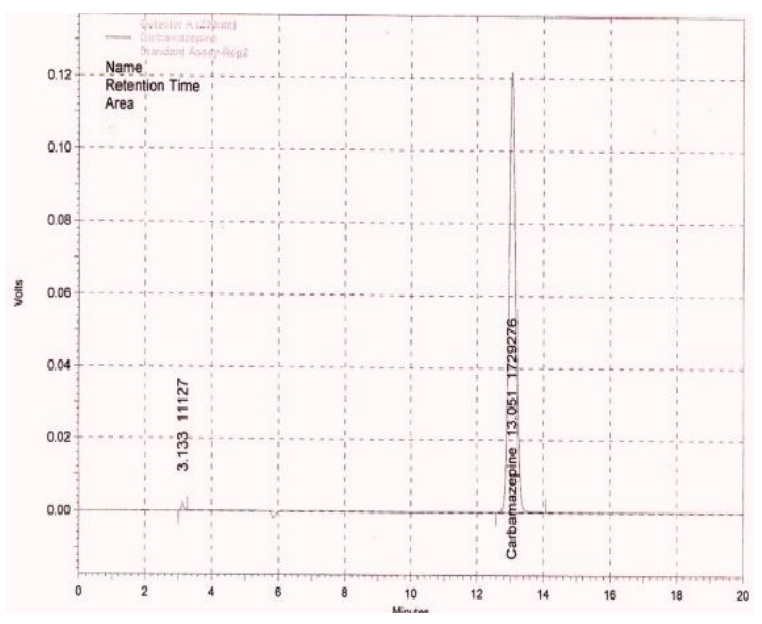

Figure 1. HPLC chromatogram of standard solution.

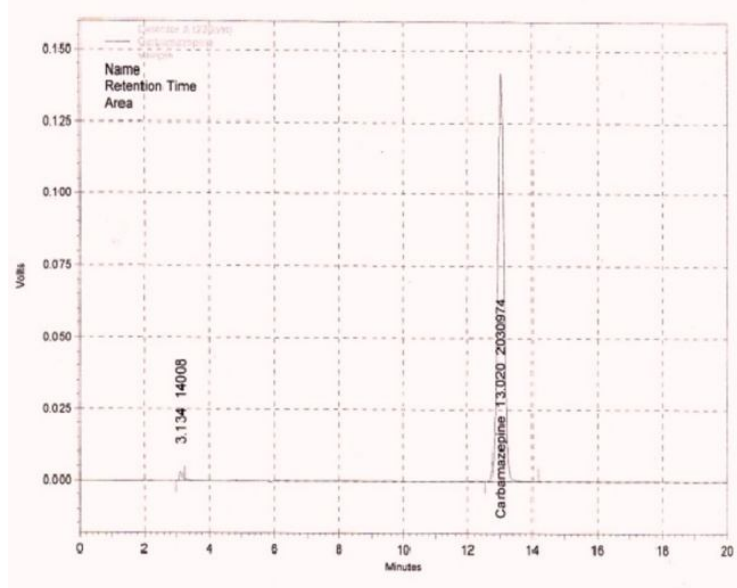

Figure 2. HPLC chromatogram of sample solution. 


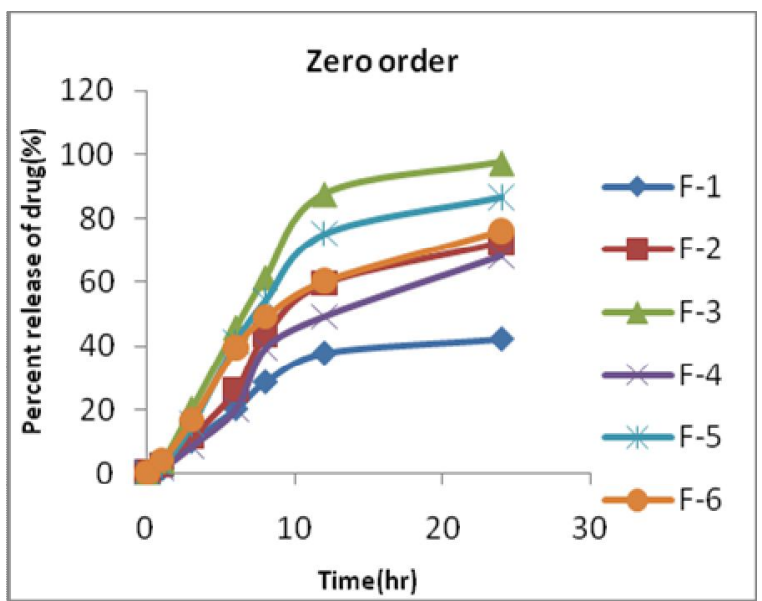

Figure 3. Zero order plot of release kinetics of formulations (F-1 to F-6).

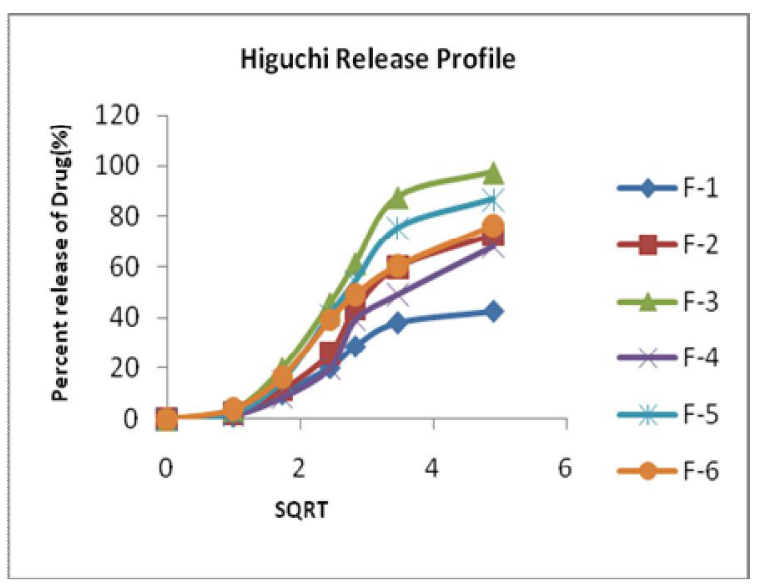

Figure 4. Higuchi plot of release kinetics of formulations (F-1 to F-6).

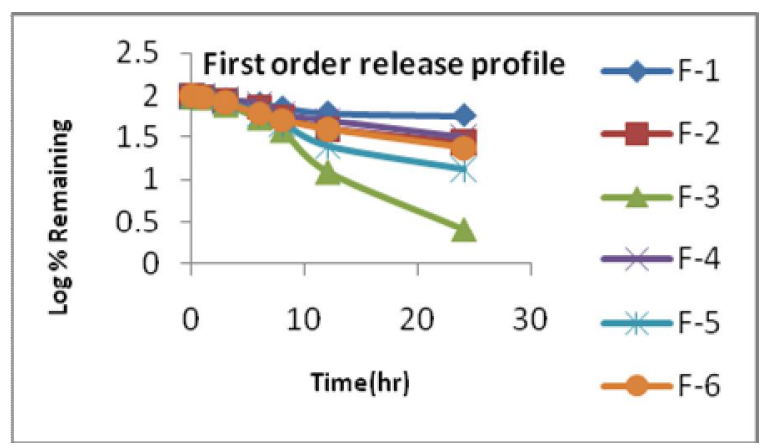

Figure 5. First order plot of release kinetics of formulations (F-1 to F-6)

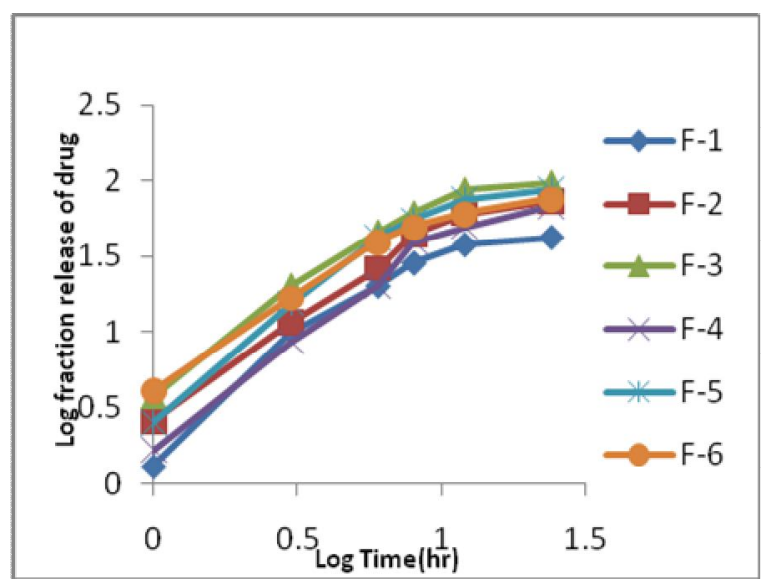

Figure 6. Korsmeyer-Peppas plot of release kinetics of formulations (F-1 to F-6).

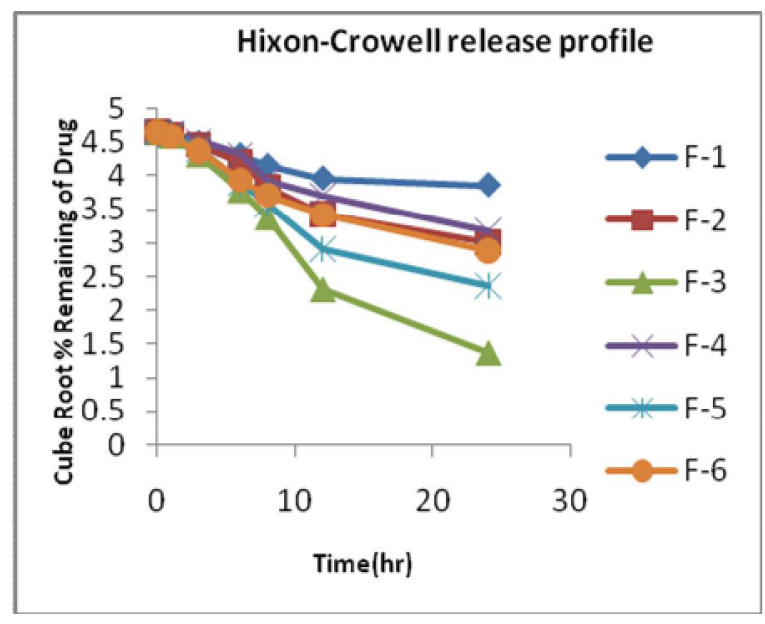

Figure 7. Hixson-Crowell plot of release kinetics of formulations (F-1 to F-6).

\section{CONCLUSION}

From the above observations an important conclusion can be drawn that an increase of SLS content increases the rate and extent of carbamazepine release from the matrix tablet. SLS had better solubilizing property on carbamazepine matrix tablet in compared to GMS. Another finding was that blending of solubilizer (SLS and GMS) and without solubilizer or surfactant did not show desire or optimum release profile after 24 hour. Among these six formulations only F-3 and F-5 met the USP specification of release profile where as the drug release from F-5 was inferior to F-3. Formulation F-3 
contained 1\% SLS and F-5 contained 1\% GMS. So it can be concluded that SLS containing formulation gave better release than GMS containing formulation. Kinetic modeling of in vitro dissolution profiles revealed the drug release mechanism followed mainly super case II transport which was dependent on the type and amount of polymer used. Thus, a suitable combination of polymer, SLS and GMS can give us matrix system with desirable drug release. The optimized formulations may be used for the development of carbamazepine extended release tablet for commercial production in order to combat epilepsy and treatment of partial and tonic-clonic seizures.

\section{ACKNOWLEDGEMENT}

The authors wish to thank Incepta Pharmaceuticals Limited, Dhaka, Bangladesh for providing raw materials and also for technical support.

\section{REFERENCES}

1. Amidon, G.L., Lennernas, H., Shah, V.P. and Crison, J.R. 1995. A theoretical basis for a biopharmaceutical drug classification: the correlation of in vitro drug product dissolution and in vivo bioavailability, Pharm. Res. 12, 413420 .

2. Leuner, C. and Dressman, J. 2000. Improving drug solubility for oral delivery using solid dispersions, Eur. J. Pharm. Biopharm. 50, 47-60.

3. Wyatt, D.A. 1999. Taking poorly water soluble compounds through discovery: recent advances in the formulations and development of poorly soluble drugs. Bulletin Technique Gattefosse 31-39.

4. Craig, D.Q.M. 1993. The use of self-emulsifying systems as a means of improving drug delivery. Bulletin Technique Gattefosse 21-31.

5. Aunins, J.G., Southard, M., Meyers, R.A., Hemmelstein, K.J. and Stella, V.J. 1985. Dissolution of carboxylic acids III. The effect of polyionizable buffers. J. Pharm. Sci. 74, 1305-1316.

6. Castillo, J.A., Palomo-Canales, J., Garcia, J.J., Lastres, J.L., Bolas, F. and Torrado, J.J. 1999. Preparation and characterization of albendazole $\beta$-cyclodextrin complexes. Drug Dev. Ind. Pharm. 25, 1241-1248.
7. Chen, L.R., Wesley, J.A., Bhattachar, S., Ruiz, B., Bahash, K. and Babu, S.R. 2003. Dissolution behavior of a poorly water soluble compound in the presence of Tween 80, Pharm. Res. 20, 797-801.

8. Crison, J.R., Weiner, N.D. and Amidon, G.L. 1997. Dissolution media for in vitro testing of water-insoluble drugs: effect of surfactant purity and electrolyte on in vitro dissolution of carbamazepine in aqueous solutions of sodium lauryl sulfate. J. Pharm. Sci. 86, 384-388.

9. Jain, A.C. and Adeyeye, M.C. 2001. Hygroscopicity, phase solubility and dissolution of various substituted sulfobutylether $\beta$ - cyclodextrins (SBE) and danazol-SBE inclusion complexes. Int. J. Pharm. 212, 177-186.

10. Qazi, S., Peter Samuel, N.K., Venkatachalam, T.K. and Uckun, F.M. 2003. Evaluating dissolution profiles of an antiHIV agent using ANOVA and non-linear regression models in JMP software. Int. J. Pharm. 252, 27-39.

11. Serajuddin, A.T. and Rosoff, M. 1984. pH-solubility profile of papaverine hydrochloride and its relationship to the dissolution rate of sustained-release pellets. J. Pharm. Sci. 73, 1203-1208

12. Hite, M., Turner, S. and Federici, C. 2003. Part 1: Oral Delivery of Poorly Soluble Drugs, PMPS Summer, pp 38-40.

13. Baveja, S.K. and Ranga, K.V. 1986. Effect of additives on release of centperazine from matrix tablets. Indian J. Pharm. Sci. 48, 69-71.

14. Najib, N. and Suleiman, M.S. 1985. Kinetics of drug release from ethylcellulose solid dispersions. Drug Dev. Ind. Pharm. 11, 2169-81.

15. Nokhodchi, A., Khaseh, P., Ghafourian, T. and SiahiShadbad, M.R. 1999. The role of various surfactants and fillers in controlling the release rate of theophylline from HPMC matrices. STP Pharma. Sci. 9, 555-60.

16. Shah, D., Shah, Y. and Pradhan, R. 1997. Development and evaluation of controlled-release diltiazem $\mathrm{HCl}$ microparticles using cross-linked poly (vinyl alcohol). Drug Dev. Ind. Pharm. 23, 567-574.

17. Martin, A. 2001. Micromeritics. In: Martin A, ed. Physical Pharmacy. Balti-more, MD: Lippincott Williams \& Wilkins, 423-454.

18. Raslan, H.K. and Maswadeh, H. 2006. In vitro dissolution kinetic study of theophylline from mixed controlled release matrix tablets containing hydroxypropylmethyl cellulose and glyceryl behenate, Indian J. Pharm. Sci. 68, 308-312.

19. Banker, G.S. and Anderson, N.R. 1986. Tablets. In: The Theory and Practice of Industrial Pharmacy (Lachman L, Lieberman H.S., Kanig J.L., Eds.), 3rd edn. Philadelphia, Lea \& Febiger; 1986. pp. 293-345.

20. Clara, I., Vargas, and Evone, S. 1999. Kinetic release of theophylline from hydrophilic swellable matrices, Drug Dev. Ind. Pharm. 25, 1045-1050. 